\title{
AS PRÁTICAS DA GESTÃO DA SEGURANÇA EM OBRAS DE PEQUENO PORTE: INTEGRAÇÃO COM OS CONCEITOS DE SUSTENTABILIDADE.
}

\author{
QUELHAS; Osvaldo Luiz Gonçalves, D.Sc. \\ Professor do Mestrado em Engenharia Civil da Universidade Federal Fluminense \\ Caixa Postal 100175, CEP 24001-970, Niterói, RJ \\ quelhas@1atec.uff.br
}

ALVES; Micheli Soares

Engenheira Civil, Mestrado em Engenharia Civil da Universidade Federal Fluminense micheli_sa@yahoo.com.br

FILARDO; Paulo Schmitt

Engenheiro Civil, Mestrado em Engenharia Civil da Universidade Federal Fluminense filardopaulo@hotmail.com

\begin{abstract}
This work presents reflections about safety performance at building site as a result of social responsibility practices, personnel management and environmental management. These management systems compose the nucleus of what is so-called sustainability. From examples gathered by field research, bibliographical research and consolidation in research groups in which the authors belong, conclusions are present as a contribution to the improvement of Security Management and Occupational Health Management integrated to Business Management.
\end{abstract}

Key words: Business Social Responsibility; Sustainable Business Management; Security Performance. 


\section{RESUMO}

Este trabalho apresenta reflexões acerca do desempenho da segurança no canteiro de obras como resultado das práticas de responsabilidade social, de gestão de pessoas, da gestão ambiental. Tais sistemas de gestão constituem o núcleo do que atualmente se denomina sustentabilidade organizacional. A partir de exemplos coletados em pesquisa de campo, de pesquisa bibliográfica e de consolidação nos grupos de pesquisa aos quais pertencem os autores apresentam conclusões como contribuição para o aperfeiçoamento da Gestão da Segurança e da Saúde Ocupacional integrada à Gestão dos Negócios.

Palavras-chave: Responsabilidade Social Empresarial; Gestão de Negócios Sustentáveis; Desempenho em Segurança.

\section{INTRODUÇÃO}

Mais do que cumprir a legislação existente, é um dever da alta administração das empresas proporcionar um ambiente de trabalho seguro e saudável (ALEVATO, 1999). Na atualidade as organizações buscam aperfeiçoar-se através de seus modelos de gestão, incorporando os conceitos das boas práticas de relacionamento com empregados, sociedade, governo, acionistas, fornecedores e concorrentes. Tal escopo de atuação denominou-se recentemente como "responsabilidade organizacional".

Tal ambiente de pró-atividade no que se refere à prevenção de acidentes de proteção à saúde do trabalhador é resultante do compromisso e da colaboração mútua entre os empregadores e trabalhadores.

Ao projetar e construir novos locais de trabalho, sistemas de produção ou modificar os existentes deve-se levar em consideração aos fatores que podem comprometer o exercício de uma determinada tarefa em função das limitações pessoais e operacionais existentes.

Cada vez mais, se destacam as preocupações do governo, empresários e sindicatos em melhorar a segurança, a saúde e as condições do meio ambiente de trabalho. Para isto é necessário um planejamento que permita a participação da alta administração e dos empregados para encontrar as soluções práticas e economicamente viáveis. 
A melhoria da segurança, saúde e meio ambiente de trabalho além de aumentar a produtividade, diminui o custo do produto final, pois diminui as interrupções no processo, absenteísmo e acidentes e/ou doenças ocupacionais (BERGAMINI, 1997).

Os aspectos preventivos envolvidos na segurança do trabalho buscam minimizar os riscos e as condições inadequadas e incorporar a melhoria contínua das condições de trabalho introduzindo requisitos mínimos de segurança cada vez mais rígidos.

Os riscos de acidentes com lesão, problemas ergonômicos e organizacionais podem ser identificados pela inspeção sistemática do local de trabalho. As inspeções de segurança são umas das medidas preventivas mais importantes para assegurar um local de trabalho seguro. A natureza do trabalho determinará com que freqüência às inspeções de segurança devem ser realizadas.

Algumas empresas possuem profissionais de medicina e enfermagem do trabalho ligados ao SESMT - Serviços Especializados em Engenharia de Segurança e em Medicina do trabalho gerenciando o serviço de saúde, ambulatórios e instalações de reabilitação, nas pequenas empresas estes serviços são terceirizados. A função principal do serviço de saúde ocupacional é cooperar com a gerência e com os trabalhadores, atuando na prevenção e contribuindo para a melhoria contínua da segurança e condições de trabalho.

As boas práticas de segurança e higiene ocupacional são importantes para evitar acidentes e garantir a saúde dos trabalhadores tendo como "produtos" a motivação e o comprometimento (MASLOW, 1970). As boas práticas de segurança estão associadas com a melhoria das condições de trabalho. Subestimar ou ser indiferente aos riscos do ambiente de trabalho cria um ambiente propício à ocorrência de acidentes.

Muitas organizações no Brasil ainda têm uma visão restrita em relação à segurança, medicina do trabalho e saúde ocupacional. O tratamento dessas questões se restringe à coleta de dados estatísticos, ações reativas a acidentes do trabalho e respostas a causas trabalhistas. Segurança e saúde ocupacional inicia-se como sistema de gestão através de normas como a OHSAS 18001 (Occupational Health and Safety Assessment Series) e BS 8800 (British Standard), além do Prêmio 
Nacional de Segurança e Saúde Ocupacional.

\subsection{Formulação da Situação-Problema}

Identifica-se a problemática na carência na literatura que propõe critérios de gestão para a construção civil de uma abordagem sistêmica e refinada no que diz respeito à integração das ações de prevenção de segurança e de saúde com os princípios norteadores do negócio. Torna-se coerente a escolha de tal problema quando se constata que para uma organização ser sustentável é necessário que possua garantia de que suas operações não irão provocar ações futuras no que se refere a suas práticas em relação aos trabalhadores( passivos trabalhistas), ao meio ambiente( passivos ambientais), quanto à continuidade de disponibilidade de bons fornecedores, na construção de imagem positiva junto à opinião pública e quanto ao cumprimento da legislação e ao recolhimento de taxas e impostos.

\subsection{Objetivos, Delimitações e Importância do Estudo}

Buscou-se consolidar os conceitos e conclusões desenvolvidos nos grupos de pesquisa nos quais os autores deste trabalho atuam e com a citação e descrição de casos coletados em pesquisa de campo.

Objetiva-se a partir da análise da prática de segurança e saúde ocupacional de uma pequena empresa construtora, a qual não possui sistemas de gestão, avaliar o quão distante do ideal proposto pela norma está a realidade de suas obras. Fizeram-se sugestões em caráter de adequação da organização à norma BS 8800 .

$\mathrm{O}$ resultado final constitui-se em contribuição ao pensamento gerencial em franco desenvolvimento no que se refere à Construção Sustentável.

\subsection{Questões e/ou Hipóteses}

Quais as atitudes dos responsáveis na obra? Elas indicam uma preocupação com segurança? Possuem uma visão sistêmica?

No núcleo dos trabalhadores há uma cultura da segurança e saúde 
ocupacional? Eles possuem uma política de conduta que os guia? Se possuírem, ela é bem entendida?

Há padronização de processos? Se há, isso contribui efetivamente para a segurança e saúde ocupacional?

A realidade das obras é adequada à legislação?

\section{REVISÃO DA LITERATURA}

Constitui-se estrutura principal desta revisão a apresentação de conceitos relativos à responsabilidade organizacional (ou corporativa), ética empresarial, gestão sustentável, gestão da segurança e saúde ocupacional e a fundamentação do triple bottom line.

Torna-se igualmente importante para o entendimento da contribuição deste trabalho a visualização do PDCA com suas etapas didaticamente explicitadas para compor um ciclo de gerenciamento que garante o aperfeiçoamento continuo e a manutenção da rotina.

\subsection{Responsabilidade Social Organizacional}

A responsabilidade social de uma organizacional consiste na decisão de participar mais diretamente das ações comunitárias na região em que está inserida e diminuir possíveis danos ambientais decorrente do tipo de atividade que exerce. Mas, apoiar o desenvolvimento da comunidade e preservar o meio ambiente não são suficientes para atribuir a uma empresa a condição de socialmente responsável. É necessário investir no bem-estar de seus empregados e dependentes e num ambiente de trabalho saudável, além de dar retorno aos seus acionistas e garantir a satisfação dos seus clientes e/ou consumidores.

O exercício da responsabilidade social pressupõe uma atuação eficaz da organização em duas dimensões: a gestão de responsabilidade interna e gestão de responsabilidade externa.

A responsabilidade social interna caracteriza o estágio inicial da cidadania 
empresarial. Entretanto, não é sempre que ocorre este movimento. Muitas organizações cometem um sério erro de estratégia social e invertem este processo, causando um grande descontentamento entre os empregados, confirmando um grave quadro de conflitos, ansiedade e desmotivações.

A responsabilidade social interna tem como foco trabalhar o público interno da organização, desenvolver um modelo de gestão participativa e de reconhecimento de seus empregados, promovendo comunicações transparentes, motivando-os para um desempenho ótimo. Este modelo de gestão interna compreende ações dirigidas aos empregados e dependentes, aos funcionários de empresas contratadas, terceirizadas, fornecedoras e parceiras.

$\mathrm{Na}$ ligação entre a realidade social, política, econômica e cultural da organização as ações de responsabilidade social interna podem começar por:

- cuidar da qualidade de vida do empregado e investir nas instalações sanitárias;

- atender às necessidades básicas dos empregados criando uma infra-estrutura de refeitório para seu público interno, empresas terceirizadas, contratadas e fornecendo cesta básica para seus dependentes;

- criar o hábito de uso do uniforme contribuindo para melhorar as condições de segurança no trabalho;

- buscar um Plano de Saúde e assistência odontológica que atenda a todos os empregados e familiares;

- cuidar da condição de moradia dos empregados;

- implantar um Plano de Cargos e Salários;

- implantar programas de reconhecimento e valorização do empregado como: Café com o Presidente, Empregado Destaque, Ginástica na Empresa, Participação nos Resultados;

- investir na qualificação dos empregados através de programas de treinamento, internos e/ou externos e capacitação visando a sua maior qualificação profissional e obtenção de escolaridade mínima.

O desenvolvimento dessas ações é também chamado de trabalho de endomarketing, onde a organização leva motivação para o seu ambiente interno e cria uma relação de confiança com o empregado. Com isso, a organização ganha a 
sua dedicação, empenho, lealdade e aumento de produtividade.

A partir do desenvolvimento e implantação destas ações de gestão interna, a empresa pode realizar ações sociais que beneficiem a comunidade passando a exercitar a sua responsabilidade social externa. Através de um planejamento de marketing social, a organização, atendendo à sua missão, crenças e à demanda de necessidades da comunidade, atua nas áreas de educação, saúde, assistência social e ecologia, desenvolvendo ações empresariais, visando maior retorno de imagem e publicitário.

A organização pode realizar estas ações através de:

- doações de produtos, equipamentos e materiais em geral;

- transferência de recursos em regime de parceria para órgãos públicos e ONG's beneficiando escolas públicas, visando educação com qualidade, viabilizando cursos técnicos, estágios e a formação de futuros profissionais;

- prestação de serviços voluntários para a comunidade pelos empregados da organização, reformando creches e asilos;

- aplicação de recursos em atividades de preservação do meio ambiente, adotando uma praça, reciclando o lixo da empresa ou através da coleta seletiva;

- patrocínio para projetos sociais do governo;

- investimentos diretos em projetos sociais criados pela própria organização;

- investimentos em programas culturais através da lei do incentivo à cultura.

Ao participar de ações sociais, a organização além de adotar um comportamento ético e contribuir para o desenvolvimento econômico, atua na dimensão social do desenvolvimento sustentável, melhorando a qualidade de vida de seus empregados e de suas famílias, da comunidade local e da sociedade como um todo, exercendo a sua responsabilidade social.

Uma empresa responsável tem no seu compromisso, com a promoção da cidadania e o desenvolvimento da comunidade, o seu diferencial competitivo, buscando, desta forma, ser uma organização que investe recursos financeiros, tecnológicos e mão-de-obra em projetos de interesse público. É uma organização que cria um ambiente agradável de trabalho valorizando seus talentos e é capaz de desenvolver um modelo de gestão integrado onde as pessoas têm um papel decisivo 
no seu compromisso com relação à comunidade e à sociedade em geral.

\subsection{A segurança do trabalho}

A melhoria nas condições do ambiente e do exercício do trabalho tem como objetivos principais diminuir o custo social com acidentes de trabalho, valorizar a auto-estima e proporcionar a melhoria contínua da qualidade de vida dos trabalhadores.

A evolução social nas relações de trabalho não deve ser vista pelo Estado como mais um programa de governo e sim, como um objetivo nacional constante, associando o desenvolvimento às melhorias nas condições de vida da sociedade. Este compromisso nacional exige o exercício da cidadania, pois cabe a cada um de nós, agentes potenciais de transformação, governo, empregador ou trabalhador, contribuir pela melhoria da qualidade de vida e a formação de uma sociedade mais sadia e produtiva.

Especificamente na área de segurança e saúde no trabalho, o Governo está direcionando a fiscalização para setores econômicos com maior taxa de freqüência de acidentes (incidência de acidentes incluindo doenças ocupacionais), ampliando a participação da sociedade produtiva nas propostas de modernização da legislação trabalhista com o objetivo de reduzir as situações de risco. Não podemos esquecer que o atendimento às necessidades básicas do trabalhador é fator fundamental para se ter uma sociedade sadia e produtiva.

\subsection{A norma BS 8800}

A norma britânica BS 8800 foi a primeira tentativa de se estabelecer uma referência normativa para implementação de um sistema de gestão de segurança, saúde e meio ambiente. Esta norma vem sendo utilizada na implementação de um sistema de gestão de segurança e saúde visando a melhoria contínua das condições do meio ambiente de trabalho. Os princípios desta norma estão alinhados com os conceitos e diretrizes das normas da série ISO 9000 (Sistema da Qualidade) e série ISO 14000 (Gestão Ambiental). 
A norma britânica BS 8800, que continua válida, motivou diversas entidades normativas a elaborar em 1988 um conjunto de normas entituladas de OHSAS Occupational Health and Safety Assessment Series, visando a realização de auditorias e a certificação de programas de gestão de segurança, saúde e meio ambiente.

O princípio básico de um sistema de gestão baseado em aspectos normativos envolve a necessidade de determinar parâmetros de avaliação que incorporem não só os aspectos operacionais, mas também, a política, o gerenciamento e o comprometimento da alta administração com o processo e mudança e melhoria contínua das condições de segurança, saúde e trabalho. Este aspecto é de fundamental importância, pois na maioria das vezes, estas melhorias exigem além do comprometimento, altos investimentos que necessitam de planejamento no curto, médio e longo prazo para a sua execução.

Com esta nova visão, que muitas empresas já vem adotando, todos dentro do processo produtivo são responsáveis no mesmo nível de importância, principalmente os gerentes e supervisores. A administração deve identificar os riscos e orientar os trabalhadores com atitudes pró-ativas, dando o exemplo a ser seguido dentro da organização, mesmo por que, não são todas as empresas que são obrigadas pela legislação a possuir em seus quadros um profissional de segurança.

Segundo a norma britânica BS 8800, as organizações não atuam isoladamente, ou seja, diversas partes podem ter um interesse legítimo na implantação de um sistema de gestão. Essas partes são empregados, consumidores, clientes, fornecedores, comunidade, acionistas, empreiteiros, assim como as agências governamentais encarregadas de zelar pelo cumprimento dos regulamentos e leis.

A norma BS 8800 é um guia que se destina a ajudar as organizações a desenvolverem uma abordagem do gerenciamento de segurança e saúde ocupacional que permita proteger os empregados cuja saúde e segurança podem ser afetadas pelas atividades da organização. Muitas das características do gerenciamento de segurança e saúde ocupacional se confundem com práticas sólidas de gerência defendidas por proponentes da excelência da qualidade e dos negócios.

Os elementos apresentados na norma são essenciais para um sistema de gerenciamento eficaz. Os fatores humanos, incluindo a cultura, a política, e outros 
dentro das organizações, são fatores decisivos para a eficácia do sistema de gerenciamento e precisam ser considerados quando da implementação da norma.

Um ciclo de aperfeiçoamento contínuo do gerenciamento e a sua integração no sistema global de gerência são mostrados na figura 1, considerando-se todos os estágios de implementação.

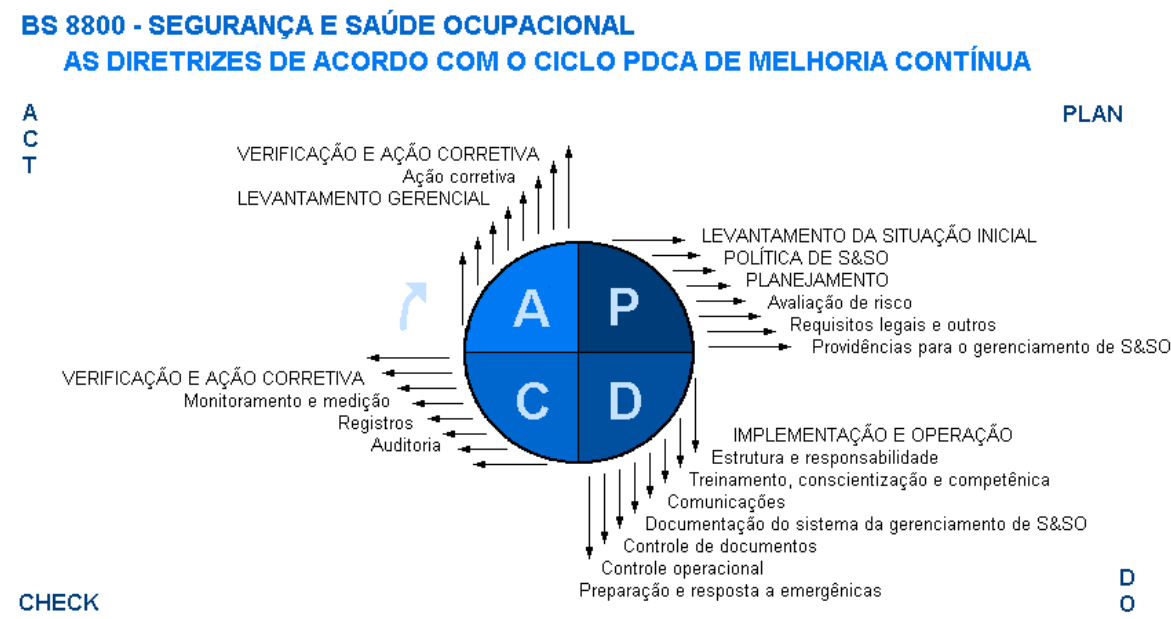

Figura 1 - PDCA aplicado especificamente ao gerenciamento de Segurança e Saúde Ocupacional.(BS 8800)

O texto da norma se divide em capítulos de 1 a 4, que tratam do escopo, referências normativas, definições e os itens que devem ser observados no sistema de gestão.

O primeiro capítulo trata do escopo da norma, que é a orientação sobre o desenvolvimento de sistemas de gerenciamento de segurança e saúde ocupacionais e as ligações com outras normas de sistemas de gerenciamento. Seu uso é possível a qualquer organização, independente do porte e da natureza de suas atividades. Não estabelece critérios de desempenho, nem tampouco orientação detalhada sobre a concepção de sistemas de gerenciamento gerais.

No segundo capítulo, a norma menciona que faz referência a publicações que proporcionam informações ou orientação mais detalhada, que poderão ser consultadas complementarmente.

A norma traz ainda uma série de definições no capítulo 3, do que são: acidente, auditoria, fatores externos, perigo, identificação de perigo, objetivos de 
saúde e segurança, vigilância de saúde, problema de saúde, incidente, fatores internos, sistema de gerenciamento, organização, risco, avaliação de riscos, levantamento da situação, alvo.

O capítulo 4 da norma traz as diretrizes que a empresa deve seguir, tendo como base para sua organização a norma ISO 14000 .

\subsection{Sustentabilidade das Organizações}

\subsubsection{Desenvolvimento Sustentável}

Existem inúmeras definições de Desenvolvimento Sustentável, elaboradas por diferentes setores da sociedade.O conceito de desenvolvimento sustentável foi apresentado pela Comissão Mundial sobre o Meio Ambiente, em abril de 1987, na Assembléia Geral das Nações Unidas. O principal produto desta Comissão foi o "Relatório Nosso Futuro Comum", também conhecido como "Relatório Brundtland", onde o desenvolvimento sustentável é apresentado como "o desenvolvimento que preenche as necessidades do presente, sem comprometer a habilidade das gerações futuras de preencherem suas próprias necessidades" (ONU, 1988).

O Desenvolvimento Sustentável pressupõe interdisciplinaridade, na medida em que sua evolução nos leva a trabalhar com três macro-temas que componha o chamado "triple bottom line", ou seja, os aspectos ambientais, sociais e econômicos. A sinergia entre esses aspectos permeia a aplicação do conceito de Desenvolvimento Sustentável, ou Sustentabilidade, onde quer que ele seja aplicado, tanto em nível governamental, como da sociedade civil ou na seara empresarial. Pode-se também trabalhar com outras dimensões do desenvolvimento sustentável, como por exemplo, os aspectos culturais, tecnológicos e políticos.

\subsubsection{Gestão Sustentável}

A Gestão Sustentável, conceito aplicado às organizações como um desdobramento imprescindível se articula com a Responsabilidade Social Organizacional, e deve ser entendida como o compromisso contínuo da organização 
com o seu comportamento ético e com o desenvolvimento econômico, promovendo ao mesmo tempo a melhoria da qualidade de vida de sua força de trabalho e de suas famílias, da comunidade local e da sociedade como um todo. A gestão sustentável atribui importância fundamental aos aspectos antes considerados como simples cumprimento de legislação: tais como segurança e saúde ocupacional, prevenção de acidentes ambientais e posicionamento pró-ativo em relação ao projeto de produtos eco-eficientes.

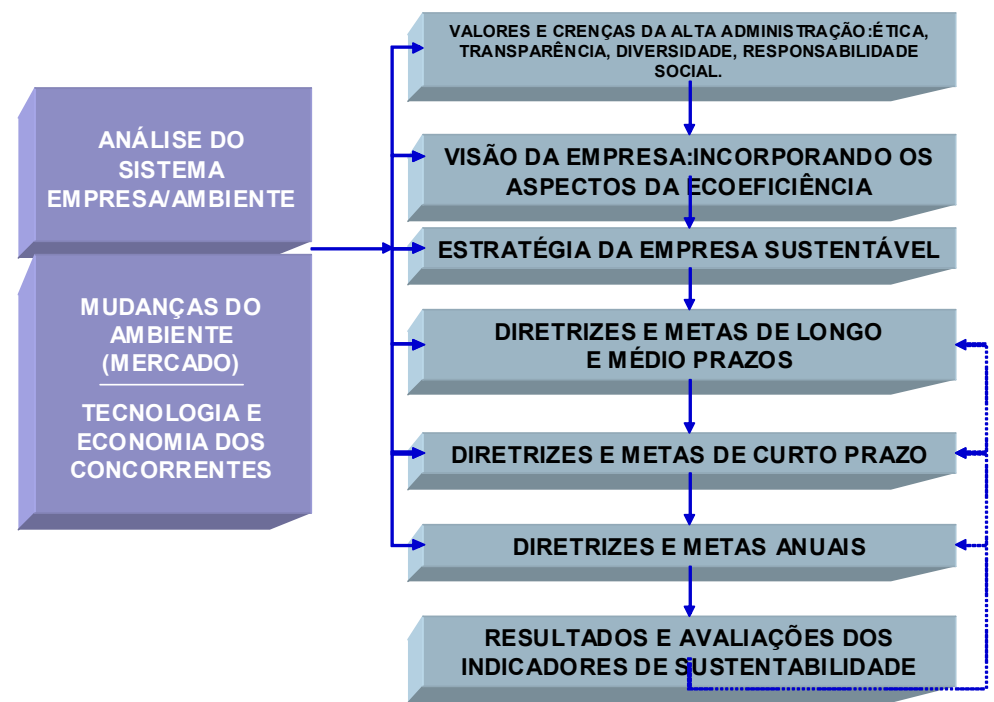

Figura 2 - Gestão estratégica da organização.

A Ecoeficiência, eixo central do conceito da Sustentabilidade, é alcançada mediante o fornecimento de bens e serviços a preços competitivos, que satisfaçam as necessidades humanas e tragam qualidade de vida, promovendo ao mesmo tempo uma redução progressiva dos impactos ambientais e da intensidade do consumo de recursos ao longo do seu ciclo de vida, a um nível, no mínimo, equivalente à capacidade de suporte estimada da Terra. Retornando ao modelo mental já plenamente conhecido do PDCA, considera-se ferramenta indispensável para a efetividade da gestão a elaboração e implementação de um sistema de indicadores. No caso deste trabalho adotou-se a base conceitual do balancec scorecard agregado com os conceitos do triple bottom line resultando em um scorecard "sustentável", 
como o apresentado na figura 3.

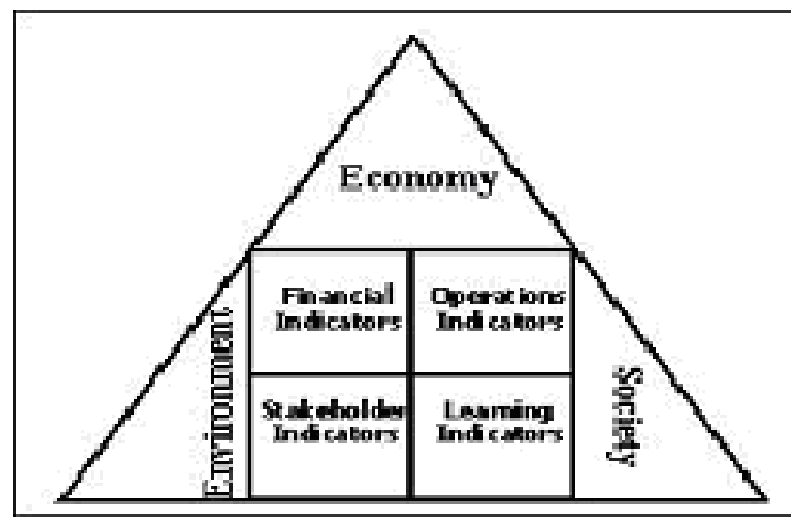

Figura 3 - Triple bottom line: Balanced Scorecard Sustentável, aspecto sistêmico de abordagem da gestão.

Indicadores de Sustentabilidade (exemplo):

- Aspectos políticos: relacionamento com o poder público, sociedade e Instituições, outras organizações;

- Econômicos: efeito dos projetos nas comunidades locais, transferência de tecnologia, capacitação de agentes na comunidade, equilíbrio receita x despesas e geração de receitas;

- Sociais: geração de oportunidades de crescimento pessoal e profissional para as pessoas e suas famílias; educação e treinamento, segurança e saúde na comunidade;

- Ecológicos: minimização de impactos sobre o meio ambiente físico e biótico, máxima valorização dos recursos energéticos renováveis, foco na eco-eficiência; - Tecnológicos: qualidade e confiabilidade adequadas e minimização de riscos de acidentes.

\section{ESTUDO DE CASO}

Foram visitadas duas obras, gerenciadas por empresas que atuam no mercado de Niterói, Estado do Rio de Janeiro. Com a participação dos engenheiros responsáveis pelo gerenciamento da produção. As duas empresas competem no mercado de pequenas construções e têm como concorrentes outras organizações que se limitam ao cumprimento da legislação de segurança e saúde ocupacional. À 
primeira observação tornam-se relevantes alguns aspectos que indicam urgente necessidade de melhoria e que são relacionados ao processo produtivo e à forma de execução das tarefas: projeto ergonômico do posto de trabalho, programação de jornada de trabalho, aspectos psíquicos e sociais além da fadiga ocupacional. Tais fatores, que influenciam na produtividade devem ser avaliados com o objetivo de sugerir medidas para adequar o trabalho à limitação pessoal dos trabalhadores.

Quanto à existência de planejamento nas práticas de segurança e saúde ocupacional, nas empresas analisadas, torna-se explícita a necessidade de que os profissionais que aí conduzem as inspeções de saúde sejam responsáveis por organizar medidas de primeiros socorros, no caso de acidentes ou doenças ocupacionais, bem como orientar na aquisição do equipamento e organização dos locais de trabalho e suas tarefas. Ou seja, é imprescindível a aplicação de ferramentas gerenciais, tais como indicadores, sistemas de informação e o treinamento de tais profissionais de saúde e de segurança nos conceitos de gestão de negócios e de planejamento estratégico para que os mesmos tenham condições de rever e de argumentar no desenvolvimento de uma cultura de prevenção pró ativa.

Um elemento importante a favor da segurança, saúde e melhoria das condições de trabalho é a informação. A empresa deve possuir mecanismos internos para divulgar os objetivos, indicadores de desempenho e resultados, estimulando a participação dos trabalhadores. Uma informação bem elaborada contribui para a conscientização de segurança dos trabalhadores e seus superiores. Além da informação deve-se criar mecanismos, como por exemplo caixas de sugestões, permitindo que os trabalhadores apresentem suas propostas reconhecendo aquelas que forem implementadas na prática.

Nas empresas analisadas as informações existentes limitavam-se ao estritamente necessário ao cumprimento das obrigações legais e trabalhistas.

O principal desafio dos supervisores é como obter e manter o cumprimento da legislação e das normas internas dentro da empresa. O principal aspecto nesta questão é garantir que estes líderes sejam o exemplo dentro da organização através de atitudes pró-ativas com a questão da segurança, saúde e melhoria nas condições de trabalho.

A alta administração da empresa por sua vez deve determinar as diretrizes 
através de uma política de segurança, saúde e meio ambiente. As pessoas estão muito mais disponíveis a cumprir as normas e procedimentos quando possuem o exemplo dos líderes da organização em todos os seis níveis.

Um dos aspectos básicos no gerenciamento é não concentrar esforços nas conseqüências e sintomas e sim nas causas, procurando entender porque as pessoas deixam de cumprir os padrões de desempenho ou não fazem o que se supõe que deveriam fazer.

A análise crítica do planejamento das obras quanto aos aspectos ambientais, se segurança e de saúde ocupacional, assim como a simples avaliação das causas de acidentes inexiste como prática gerencial nas empresas analisadas.

Constatou-se que os trabalhadores possuem uma grande deficiência de informação, motivação e treinamento. Cabe às empresas criar mecanismos alternativos para garantir a melhoria contínua dos recursos humanos, pois eles são o seu maior patrimônio.

No quadro 1 , apresentado a seguir, explicitam-se as práticas de saúde e segurança ocupacional nas empresas analisadas, confrontando-se essas constatações com as diretrizes da BS 8800. estruturou-se um quadro onde a primeira coluna apresenta a diretriz da BS 8800, a segunda a prática das obras e na terceira a deficiência da segunda em relação à primeira.

Quadro 1: Práticas em canteiro de obras x recomendações da BS 8800.

\begin{tabular}{||c|c|c||}
\hline DIRETRIZES DA NORMA BS & $\begin{array}{c}\text { PRÁTICAS DE S\&SO NAS } \\
\text { OBRAS }\end{array}$ & $\begin{array}{c}\text { DEFICIÊNCIAS A SEREM } \\
\text { SUPRIDAS }\end{array}$ \\
\hline 4.0 INTRODUÇÃO & \\
4.0.1 Generalidades & \\
Todos os elementos deste guia \\
deverão ser incorporados no sistema \\
de gerenciamento de S\&SO, mas a \\
maneira e extensão pelas quais os \\
elementos individuais devem ser \\
aplicados, dependerão de fatores \\
como o tamanho da organização, a \\
natureza das suas atividades, os \\
perigos e condições nas quais opera.
\end{tabular}




\begin{tabular}{|c|c|c|}
\hline 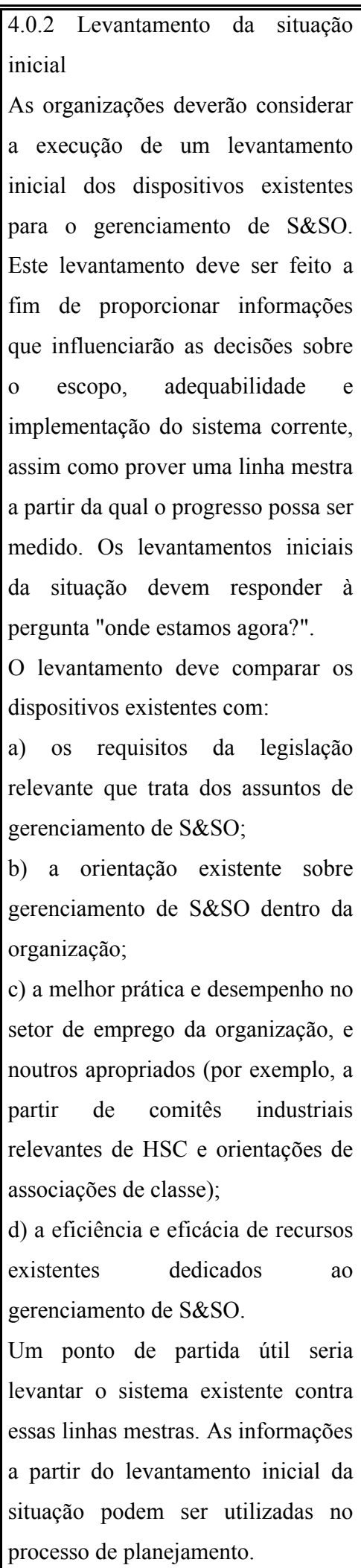 & $\begin{array}{l}\text { a) quanto aos itens da legislação } \\
\text { relevante que trata dos assuntos de } \\
\text { gerenciamento de S\&SO, são todos } \\
\text { praticados. } \\
\text { b) A orientação existente sobre } \\
\text { gerenciamento de S\&SO é exercida } \\
\text { pelo engenheiro de segurança, } \\
\text { técnico de segurança, mas muito } \\
\text { pouco pelo gerente de contrato. } \\
\text { c) este item é praticado pela } \\
\text { organização em caráter mínimo, ou } \\
\text { seja, apenas orientações informais. } \\
\text { d) quanto à eficiência e eficácia de } \\
\text { recursos existentes dedicados ao } \\
\text { gerenciamento e S\&SO afirma-se } \\
\text { que os recursos existem, porém, } \\
\text { como estão vinculados ao gerente de } \\
\text { contrato e este por sua vez vislumbra } \\
\text { um prêmio por economia de sua } \\
\text { obra, acaba tornando-se sempre } \\
\text { escasso. }\end{array}$ & $\begin{array}{l}\text { Sugere-se uma participação ativa do } \\
\text { gerente de contrato quanto às } \\
\text { orientações sobre gerenciamento de } \\
\text { S\&SO. A formação de comitês } \\
\text { relevantes e o intercâmbio constante } \\
\text { com associação de classe com o } \\
\text { intuito de elaborar palestras e cursos } \\
\text { para dirimir dúvidas. Delegar plenos } \\
\text { poderes ao engenheiro de segurança } \\
\text { sobre os recursos destinados à } \\
\text { S\&SO para que o gerente de } \\
\text { contrato cumpra suas determinações } \\
\text { em caráter pleno. }\end{array}$ \\
\hline $\begin{array}{l}4.1 \text { - Política de S\&SO } \\
\text { A mais alta gerência da organização } \\
\text { deve definir, documentar e endossar }\end{array}$ & $\begin{array}{l}\text { a) a alta gerência reconhece a S\&SO } \\
\text { como parte integral do seu } \\
\text { desempenho negocial, porém, não é }\end{array}$ & $\begin{array}{l}\text { Sugere-se a definição de uma } \\
\text { política de } \mathrm{S} \& S O \text {, documentada e } \\
\text { endossada pela alta direção da }\end{array}$ \\
\hline
\end{tabular}




\begin{tabular}{|c|c|c|}
\hline 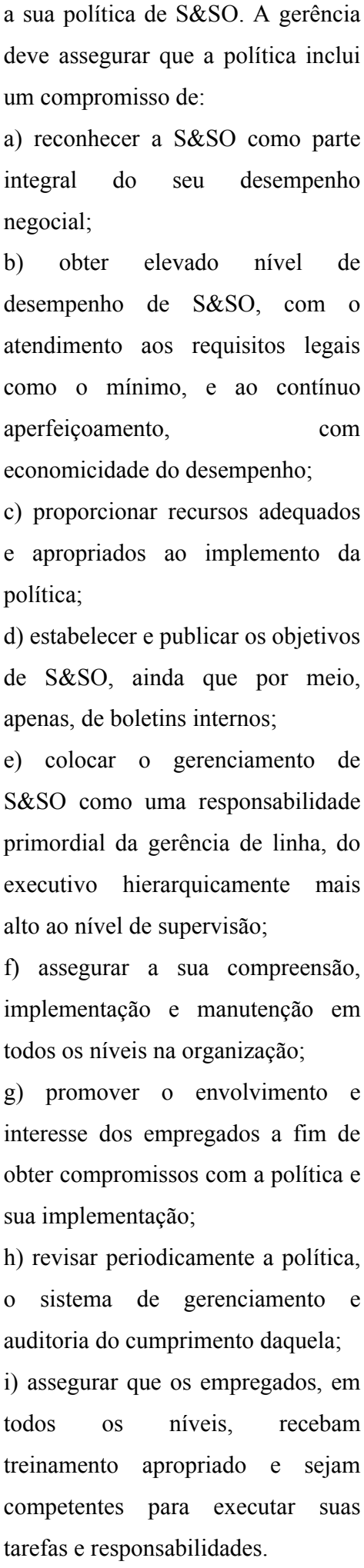 & $\begin{array}{l}\text { definida nem documentada. } \\
\text { b) nada se pode afirmar quanto ao } \\
\text { nível de desempenho, pois não há } \\
\text { indicadores. Porém afirma-se que há } \\
\text { o atendimento aos requisitos legais } \\
\text { mínimos com o contínuo } \\
\text { aperfeiçoamento e economicidade } \\
\text { de desempenho. } \\
\text { c) destina-se recurso adequado e } \\
\text { apropriado ao gerenciamento da } \\
\text { S\&SO, mas não para implemento da } \\
\text { política de S\&SO. } \\
\text { d) item não praticado. } \\
\text { e) o gerenciamento de S\&SO da } \\
\text { organização não é } \\
\text { responsabilidade do exa } \\
\text { hierarquicamente mais alto ao nível } \\
\text { de supervisão. } \\
\text { f) item não praticado. } \\
\text { g) existe o envolvimento dos } \\
\text { empregados com a S\&SO } \\
\text { h) item não praticado. } \\
\text { i) nota-se que os empregados } \\
\text { recebem treinamentos periódicos em } \\
\text { todos os níveis. }\end{array}$ & $\begin{array}{l}\text { organização. A formulação de } \\
\text { indicadores para se obter parâmetros } \\
\text { de desempenho. A criação de um } \\
\text { boletim interno para publicar os } \\
\text { objetivos de S\&SO, além de outros } \\
\text { meios que assegurem a sua } \\
\text { compreensão, implementação e } \\
\text { manutenção em todos os níveis da } \\
\text { organização. É também muito } \\
\text { importante designar o executivo de } \\
\text { mais alto nível de supervisão para o } \\
\text { gerenciamento de S\&SO. }\end{array}$ \\
\hline $\begin{array}{l}\text { 4.2 Planejamento } \\
\text { 4.2.1 Generalidades: } \\
\text { É importante que o sucesso ou o } \\
\text { fracasso da atividade planejada }\end{array}$ & & \\
\hline
\end{tabular}




\begin{tabular}{|c|c|c|}
\hline $\begin{array}{l}\text { possa ser } \text { visto claramente. } \\
\text { envolve a identificação } \\
\text { requisitos dos } \\
\text { estabelecimento de critérios claros } \\
\text { de desempenho, definindo o que } \\
\text { deve ser feito, quem é responsável, } \\
\text { quando deve ser feito e o desfecho } \\
\text { desejado.Embora seja reconhecido } \\
\text { que, na prática, organizar, planejar e } \\
\text { implementar funções estarão em } \\
\text { sobreposição, apesar disto, as } \\
\text { seguintes áreas chaves precisam ser } \\
\text { abordadas. }\end{array}$ & & \\
\hline $\begin{array}{l}\text { 4.2.2 Avaliação de risco } \\
\text { A organização deverá fazer a } \\
\text { avaliação de risco, incluindo a } \\
\text { identificação de perigos. }\end{array}$ & $\begin{array}{l}\text { A organização apresenta a avaliação } \\
\text { de risco, incluindo identificação dos } \\
\text { perigos, através do mapa de risco. }\end{array}$ & \\
\hline $\begin{array}{l}\text { 4.2.3 Requisitos legais e outros } \\
\text { A organização deverá identificar os } \\
\text { requisitos legais, além da avaliação } \\
\text { de risco, a ela aplicáveis, assim } \\
\text { como quaisquer outros requisitos } \\
\text { que considera aplicáveis ao } \\
\text { gerenciamento de S\&SO. }\end{array}$ & $\begin{array}{l}\text { A organização apresenta os } \\
\text { requisitos legais, a ela aplicáveis, } \\
\text { como por exemplo: ppra, pcmso, } \\
\text { cipa, etc. }\end{array}$ & \\
\hline $\begin{array}{l}4.2 .4 \text { Providências para o } \\
\text { gerenciamento de S\&SO } \\
\text { A organização deverá tomar } \\
\text { providências para cobrir as seguintes } \\
\text { áreas chaves: } \\
\text { a) planos e objetivos gerais, } \\
\text { incluindo pessoal e recursos, para a } \\
\text { organização implementar a sua } \\
\text { política; } \\
\text { b) ter acesso a suficiente } \\
\text { conhecimento de S\&SO, } \\
\text { capacitações e experiência para } \\
\text { administrar suas atividades com } \\
\text { segurança e segundo os requisitos } \\
\text { legais; planos operacionais para } \\
\text { c) plon de controle } \\
\text { implementar as ac̃es }\end{array}$ & $\begin{array}{l}\text { a) não há um planejamento para a } \\
\text { organização implementar sua } \\
\text { política. } \\
\text { b) a organização apresenta suficiente } \\
\text { conhecimento se S\&SO e } \\
\text { capacitação, porém, pouca } \\
\text { experiência para administrar suas } \\
\text { atividades com segurança. } \\
\text { c) item não praticado. } \\
\text { d) apesar da prática de parte das } \\
\text { atividades descritas em } 4.3 .6 \text {, estas } \\
\text { não são planejadas. } \\
\text { e)item não praticado. } \\
\text { f) aplicam-se ações corretivas, } \\
\text { porém de caráter imediatista. }\end{array}$ & $\begin{array}{l}\text { a) sugere-se que a organização, } \\
\text { através dos executivos responsáveis, } \\
\text { realize o planejamento para a } \\
\text { implementação da política de } \\
\text { S\&SO, incluindo pessoal e recursos. } \\
\text { b) a parceria junto a empresas de } \\
\text { consultoria a fim de adquirir } \\
\text { conhecimento e experiência para } \\
\text { evoluir gradativamente. } \\
\text { c) a elaboração imediata de planos } \\
\text { operacionais para implementação } \\
\text { das ações de controle dos riscos e } \\
\text { requisitos identificados. } \\
\text { d) sugere-se que seja feito o } \\
\text { planejamento destas atividades. } \\
\text { e) planejamento para medição da } \\
\text { eficiência, auditorias e levantamento }\end{array}$ \\
\hline
\end{tabular}




\begin{tabular}{|c|c|c|}
\hline $\begin{array}{l}\text { dos riscos identificados em } 4.3 .2 \text { e } \\
\text { para atender aos requisitos } \\
\text { identificados em 4.3.3; } \\
\text { d) planejamento de atividades } \\
\text { organizacionais cobertas em 4.3.6; } \\
\text { e) planejamento para a medição da } \\
\text { eficiência, auditorias e levantamento } \\
\text { da situação (veja 4.4.1, 4.4.2, } 4.4 .4 \text { e } \\
\text { 4.5); } \\
\text { f) implementar ações corretivas que } \\
\text { se demonstrem necessárias. }\end{array}$ & & $\begin{array}{l}\text { da situação a fim de criar } \\
\text { indicadores úteis à organização. } \\
\text { f) usar indicadores para criação de } \\
\text { procedimentos padronizados de } \\
\text { ações corretivas. }\end{array}$ \\
\hline $\begin{array}{l}\text { 4.3 Implementação e operação } \\
\text { 4.3.1 Estrutura e responsabilidade } \\
\text { A responsabilidade primeira quanto } \\
\text { à saúde e segurança ocupacionais } \\
\text { repousa na alta gerência. Aqui, a } \\
\text { melhor prática é atribuir a uma } \\
\text { pessoa no mais alto nível (por } \\
\text { exemplo, numa organização grande, } \\
\text { a um membro do Conselho ou da } \\
\text { diretoria) particular responsabilidade } \\
\text { por garantir que o sistema de } \\
\text { gerenciamento de S\&SO é } \\
\text { corretamente implementado e } \\
\text { funciona segundo os requisitos em } \\
\text { todos os locais e esferas de operação } \\
\text { dentro da organização.Em todos os } \\
\text { níveis da organização as pessoas } \\
\text { precisam: } \\
\text { a) responsável pela saúde e } \\
\text { segurança daqueles que dirigem, } \\
\text { delas própria e de outros com os } \\
\text { quais trabalhavam; } \\
\text { b) estar conscientes de sua } \\
\text { responsabilidade com a saúde e } \\
\text { segurança de pessoas que possam } \\
\text { ser afetadas pelas atividades que } \\
\text { controlam, como, por exemplo, } \\
\text { empreiteiros e o público; } \\
\text { c) estar conscientes da influência } \\
\text { que sua ação ou inação podem ter } \\
\text { sobre a eficácia do sistema de }\end{array}$ & $\begin{array}{l}\text { a) a organização apresenta um corpo } \\
\text { técnico responsável composto por: } \\
\text { engenheiro e técnico em segurança } \\
\text { do trabalho. } \\
\text { b) a grande maioria das pessoas está } \\
\text { consciente de sua responsabilidade } \\
\text { com a S\&SO. } \\
\text { c) a alta gerência não demonstra } \\
\text { envolvimento e atuação no } \\
\text { aperfeiçoamento contínuo do } \\
\text { desempenho da S\&SO. }\end{array}$ & $\begin{array}{l}\text { b) sugere-se aumentar a carga de } \\
\text { treinamento a fim de conscientizar a } \\
\text { totalidade, ou quase isso, das } \\
\text { pessoas envolvidas, até a } \\
\text { apresentação dos indicadores e aí } \\
\text { sim, adequar-se ao sistema. } \\
\text { c) é vital que a alta gerência } \\
\text { demonstre seu compromisso com a } \\
\text { S\&SO. O envolvimento de seu(s) } \\
\text { executivo(s) com a consciência da } \\
\text { influência que exerce(m) sobre seus } \\
\text { funcionários e conseqüentemente } \\
\text { sobre a eficácia do sistema }\end{array}$ \\
\hline
\end{tabular}




\begin{tabular}{|c|c|c|}
\hline $\begin{array}{l}\text { gerenciamento de S\&SO.A alta } \\
\text { gerência deve demonstrar, por } \\
\text { exemplo, o seu compromisso, } \\
\text { portando-se de maneira envolvida e } \\
\text { atuante no aperfeiçoamento contínuo } \\
\text { do desempenho da saúde e } \\
\text { segurança ocupacionais. }\end{array}$ & & \\
\hline $\begin{array}{l}\text { 4.3.2 Treinamento, conscientização } \\
\text { e competência } \\
\text { A organização deve tomar as } \\
\text { providências para identificar as } \\
\text { competências necessárias, em todos } \\
\text { os níveis, e organizar qualquer } \\
\text { treinamento necessário. }\end{array}$ & Item não praticado. & $\begin{array}{l}\text { Sugere-se a formulação de } \\
\text { indicadores para a organização } \\
\text { identificar competências necessárias } \\
\text { para organizar qualquer treinamento } \\
\text { necessário, em todos os níveis. }\end{array}$ \\
\hline $\begin{array}{l}\text { 4.3.3 Comunicações } \\
\text { A organização deverá estabelecer e } \\
\text { manter dispositivos, sempre que } \\
\text { apropriado, para: } \\
\text { a) a informação eficaz e, quando } \\
\text { adequado, abertas, sobre a S\&SO; } \\
\text { b) tomar as providências necessárias } \\
\text { para a provisão de consultoria por } \\
\text { especialistas; } \\
\text { c) envolver os empregados, com } \\
\text { esclarecimentos, quando adequado. }\end{array}$ & $\begin{array}{l}\text { a) item não praticado. } \\
\text { b) item não praticado. } \\
\text { c) o corpo técnico da organização } \\
\text { envolvido com S\&SO apresentou-se } \\
\text { no envolvimento com os } \\
\text { empregados e esclarecimentos } \\
\text { quando adequado }\end{array}$ & $\begin{array}{l}\text { a) sugere-se a criação imediata de } \\
\text { canais de comunicação. } \\
\text { b) fazer o levantamento das } \\
\text { necessidades e tomar providências } \\
\text { para a provisão de consultoria por } \\
\text { especialistas. }\end{array}$ \\
\hline $\begin{array}{l}\text { 4.3.4 Documentação do sistema de } \\
\text { gerenciamento de S\&SO } \\
\text { A documentação é elemento chave } \\
\text { para capacitar uma organização a } \\
\text { implementar um sistema de } \\
\text { gerenciamento bem sucedido. É } \\
\text { também importante na montagem e } \\
\text { retenção do conhecimento sobre } \\
\text { S\&SO. Contudo, é importante que a } \\
\text { documentação seja mantida num } \\
\text { mínimo necessário para eficácia. As } \\
\text { organizações devem assegurar que a } \\
\text { documentação suficiente fique } \\
\text { disponível para implementar por } \\
\text { completo os planos de S\&SO e que } \\
\text { seja proporcional às suas } \\
\text { necessidades. }\end{array}$ & Item não praticado. & $\begin{array}{l}\text { Sugere-se a parceria junto a } \\
\text { empresas de consultoria por tratar-se } \\
\text { de um elemento chave para capacitar } \\
\text { uma organização a implementar um } \\
\text { sistema de gerenciamento bem } \\
\text { sucedido. }\end{array}$ \\
\hline
\end{tabular}




\begin{tabular}{|c|c|c|}
\hline $\begin{array}{l}\text { 4.3.5 Controle de documentos } \\
\text { As organizações devem tomar as } \\
\text { providências para garantir que os } \\
\text { documentos sejam atualizados e } \\
\text { aplicáveis aos fins para os quais } \\
\text { foram criados. }\end{array}$ & Item não praticado. & $\begin{array}{l}\text { A parceria junto a empresas de } \\
\text { consultoria por tratar-se de elemento } \\
\text { chave para capacitar a organização a } \\
\text { implementar um sistema de } \\
\text { gerenciamento bem sucedido. }\end{array}$ \\
\hline $\begin{array}{l}\text { 4.3.6 Controle Operacional } \\
\text { É importante que a S\&SO, no seu } \\
\text { sentido mais amplo, seja } \\
\text { inteiramente integrada, em toda a } \\
\text { organização, e em todas as } \\
\text { atividades, a despeito do tamanho ou } \\
\text { natureza do seu trabalho. Ao } \\
\text { organizar para a implementação da } \\
\text { política e do gerenciamento efetivo } \\
\text { da S\&SO, a organização deve tomar } \\
\text { providências para assegurar que as } \\
\text { atividades são executadas com } \\
\text { segurança e de acordo com as } \\
\text { providências definidas em } 4.2 .4 \text {, e, } \\
\text { ainda: } \\
\text { a) definir a alocação de } \\
\text { responsabilidades e prestação de } \\
\text { contas na estrutura gerencial; } \\
\text { b) assegurar que as pessoas têm a } \\
\text { necessária autoridade para executar } \\
\text { as suas tarefas; } \\
\text { c) atribuir recursos compatíveis com } \\
\text { o seu tamanho e natureza. }\end{array}$ & $\begin{array}{l}\text { a) a organização define a alocação } \\
\text { de responsabilidades e prestação de } \\
\text { contas na estrutura gerencial. } \\
\text { b) a organização assegura que as } \\
\text { pessoas têm a necessária autoridade } \\
\text { para executar as suas tarefas. } \\
\text { c) a organização atribui recursos } \\
\text { compatíveis com o seu tamanho e } \\
\text { natureza. }\end{array}$ & \\
\hline $\begin{array}{l}\text { 4.3.7 Preparação e resposta a } \\
\text { emergências } \\
\text { Uma organização deve tomar } \\
\text { providências para estabelecer planos } \\
\text { de contingências em emergências } \\
\text { previsíveis e minimizar os seus } \\
\text { efeitos. }\end{array}$ & Item não praticado. & $\begin{array}{l}\text { Sugere-se o estabelecimento de } \\
\text { planos de contingências em } \\
\text { emergências previsíveis e assim } \\
\text { minimizar seus efeitos. }\end{array}$ \\
\hline $\begin{array}{l}\text { 4.4 Verificação e ação corretiva } \\
\text { 4.4.1 Monitoração e medição } \\
\text { A medição do desempenho é uma } \\
\text { maneira importantíssima de prover } \\
\text { informações sobre a eficácia do } \\
\text { sistema de gerenciamento de S\&SO. }\end{array}$ & $\begin{array}{l}\text { a) item não praticado. } \\
\text { b) item não praticado. }\end{array}$ & \begin{tabular}{|lr} 
a) criar medições & pró-ativas de \\
desempenho das & atividades \\
impactantes à S\&SO. & \\
b) criar medições & reativas de \\
desempenho que & monitorem \\
acidentes, quase & acidentes,
\end{tabular} \\
\hline
\end{tabular}




\begin{tabular}{|c|c|c|}
\hline $\begin{array}{l}\text { Medidas qualitativas e quantitativas } \\
\text { devem ser consideradas, sempre que } \\
\text { adequado, e devem ser preparadas } \\
\text { especialmente para as necessidades } \\
\text { da organização. A medição de } \\
\text { desempenho é um meio de } \\
\text { monitorar a extensão na qual a } \\
\text { política e os objetivos estão sendo } \\
\text { satisfeitos e inclui: } \\
\text { a) medições pró-ativas de } \\
\text { desempenho que monitorem o } \\
\text { atendimento, por exemplo, pela } \\
\text { vigilância e inspeções das } \\
\text { providências sobre saúde e } \\
\text { segurança da organização, como } \\
\text { sistemas seguros de trabalho, } \\
\text { autorizações para trabalhar, etc.; } \\
\text { b) medições reativas de desempenho } \\
\text { que monitorem acidentes, quase } \\
\text { acidentes, problemas de saúde e } \\
\text { outras evidências históricas de } \\
\text { saúde, desempenho deficiente de } \\
\text { saúde e segurança. }\end{array}$ & & $\begin{array}{l}\text { problemas de saúde e } \text { outras } \\
\text { evidências históricas de } \\
\text { desempenho deficiente de saúde e } \\
\text { segurança. }\end{array}$ \\
\hline $\begin{array}{l}\text { 4.4.2 Ação corretiva } \\
\text { Onde deficiências forem } \\
\text { encontradas, as causas originárias } \\
\text { devem ser identificadas e ações } \\
\text { corretivas tomadas. }\end{array}$ & $\begin{array}{l}\text { Tomam-se ações corretivas, porém } \\
\text { as causas originárias das deficiências } \\
\text { encontradas não são identificadas. }\end{array}$ & $\begin{array}{l}\text { Identificar as causas originárias em } \\
\text { deficiências encontradas e também a } \\
\text { criação de um indicador para tal fim. }\end{array}$ \\
\hline $\begin{array}{l}\text { 4.4.3 Registros } \\
\text { A organização deve manter os } \\
\text { registros necessários para } \\
\text { demonstrar o cumprimento de } \\
\text { requisitos legais, assim como de } \\
\text { outros. }\end{array}$ & $\begin{array}{l}\text { A organização deve mantêm } \\
\text { registros necessários } \\
\text { demonstrar o cumprimento de } \\
\text { requisitos legais, assim como de } \\
\text { outros. }\end{array}$ & \\
\hline $\begin{array}{l}\text { 4.4.4 Auditoria } \\
\text { Além da monitoração de rotina do } \\
\text { desempenho de S\&SO, haverá } \\
\text { necessidade de auditorias periódicas } \\
\text { que possibilitem uma avaliação mais } \\
\text { profunda e crítica de todos os } \\
\text { elementos do sistema de } \\
\text { gerenciamento de S\&SO. As }\end{array}$ & $\begin{array}{l}\text { a) item não praticado. } \\
\text { b) item não praticado. } \\
\text { c) item não praticado. } \\
\text { d) item não praticado. }\end{array}$ & $\begin{array}{l}\text { Sugere-se a criação de uma equipe } \\
\text { de auditores internos capazes de } \\
\text { realizar auditorias rigorosas, } \\
\text { contudo, numa abordagem adaptada } \\
\text { ao tamanho da organização } \\
\text { (pequeno porte). Em seguida a visita } \\
\text { de auditores externos num intervalo } \\
\text { pré-determinado a fim de melhorar }\end{array}$ \\
\hline
\end{tabular}




\begin{tabular}{|c|c|c|}
\hline 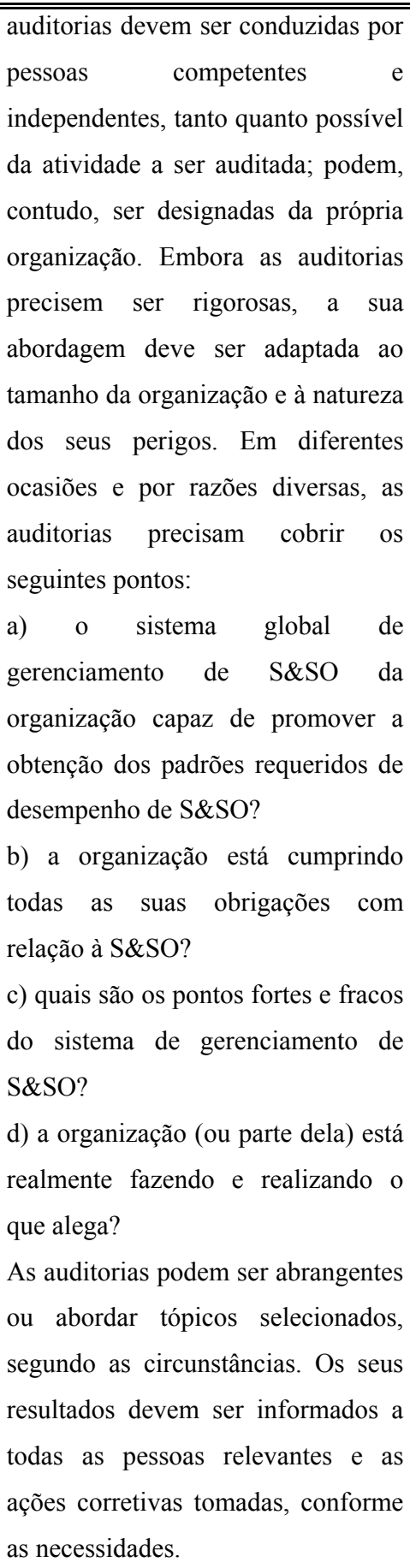 & & $\begin{array}{|lccc|}\text { continuamente } & \text { seu } & \text { sistema } & \text { de } \\
\text { S\&SO. } & & & \\
\end{array}$ \\
\hline $\begin{array}{l}\text { 4.5 Levantamento gerencial } \\
\text { A organização deverá definir a } \\
\text { freqüência e escopo dos } \\
\text { levantamentos periódicos do sistema } \\
\text { de gerenciamento de S\&SO, } \\
\text { segundo as suas necessidades. O } \\
\text { levantamento periódico da situação } \\
\text { deverá considerar: }\end{array}$ & $\begin{array}{l}\text { a) item não praticado. } \\
\text { b) item não praticado. } \\
\text { c) item não praticado. } \\
\text { d) item não praticado. }\end{array}$ & $\begin{array}{l}\text { Sugere-se que a organização defina } \\
\text { a freqüência e escopo dos } \\
\text { levantamentos periódicos do sistema } \\
\text { de gerenciamento de S\&SO, } \\
\text { segundo as suas necessidades. }\end{array}$ \\
\hline
\end{tabular}




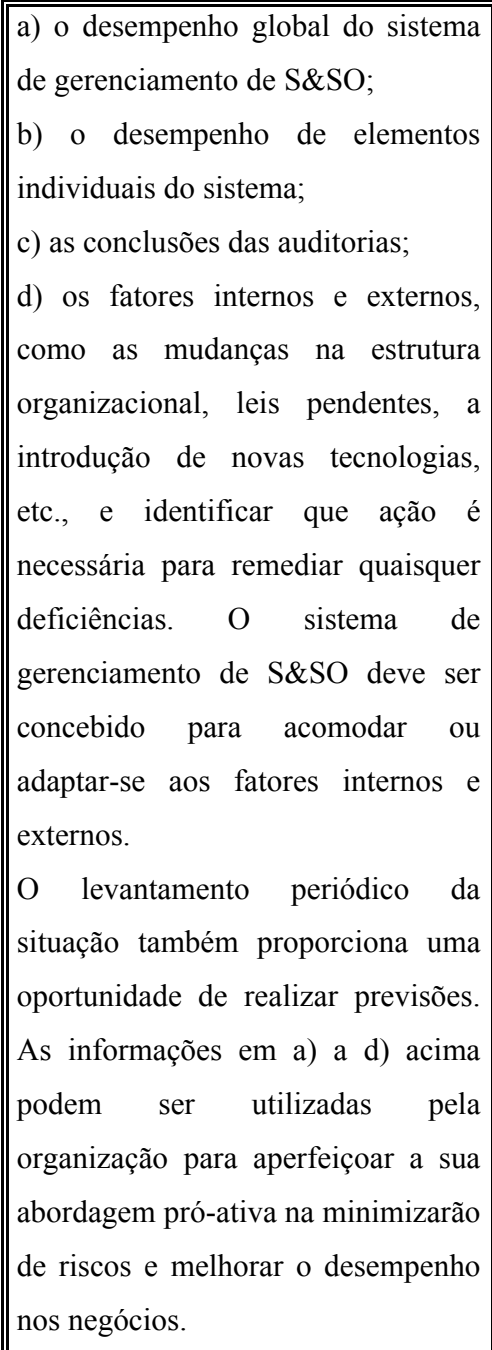

\section{CONCLUSÃO}

Conclui-se que as organizações em questão, mesmo sendo de pequeno porte, apresentam-se necessitadas de uma abordagem cientifica da administração da segurança e da saúde ocupacional e, apesar das carências, visualiza-se a possibilidade de implementação de um Sistema de Gerenciamento de Segurança e Saúde Ocupacional (SGSSO). Sugere-se de imediato o envolvimento da alta direção e a designação de um de seus membros para gerenciar o SGSSO assim como acompanhar o desempenho das ações estabelecidas pelo programa de segurança. Para isto é necessário a definição dos indicadores, a forma de acompanhar a evolução de cada um deles e divulgar para toda a organização os resultados e seus objetivos. Recomenda-se a criação de uma equipe de auditores internos e a contratação de 
auditoria externa periódica.

A padronização trará melhoras como a simplificação e otimização dos processos como, por exemplo, os serviços executados em obra. Os esforços para implementação de um SGSSO certamente serão recompensados pelo potencial de sinergia a ser auferido em planejamento estratégico, eficácia, consistência, e robustez da busca pela melhoria contínua global. Afinal, as pessoas são a essência de qualquer organização.

Considerou-se neste trabalho os indicadores relativos a segurança e saúde ocupacional, ou seja apenas aqueles recomendados para o público interno da organização. Outras pesquisas deverão ser realizadas para mapear os indicadores relativos aos outros impactados pelas operações da organização: sociedade, acionistas, clientes, fornecedores, competidores e governos.

Este artigo é o resultado parcial das pesquisas em desenvolvimento no LATEC - Laboratório de Tecnologia, Gestão de Negócios e Meio Ambiente - e indicam a sua continuidade para a definição de indicadores de ecoeficiência nos processos produtivos e de efetividade no negócio.

\section{REFERÊNCIAS BIBLIOGRÁFICAS}

[1] MASLOW, Abraham H. Motivation and Personality. $2^{\text {a }}$ ed. New York: Harperg Row, 1970.

[2] ALEVATO, Hilda Moreira R. Trabalho e Neurose: enfrentando a tortura de um ambiente em crise. Rio de Janeiro: Quartet, 1999.

[3] BERGAMINI, Cecília Whitaker. Motivação nas organizações. $4^{\mathrm{a}}$ ed. São Paulo: Atlas, 1997.

[4] PRADEZ, P. A. J. Uma norma pelo trabalho: É irreversível o uso de certificações para demonstrar compromissos. Gazeta Mercantil, 08 de maio de 2002.

[5] INSTITUTO McKINSEY. Produtividade no Brasil: a chave do desenvolvimento acelerado. Ed. Campus, Rio de Janeiro, 1999.

[6] BRITISH STANDARD. BS 8800: Diretrizes para Sistemas de Gerenciamento de Segurança e Saúde Ocupacional. 1996

[7] ARAÚJO, Giovanni Moraes de. Normas Regulamentadoras Comentadas. $3^{\text {a }}$ edição, Rio de Janeiro, 2002.

[8] . SINDUSCON - Sindicato da Indústria da Construção Civil do estado do Rio de Janeiro. Net, Rio de janeiro, dezembro de 2002. Seção Serviços e Produtos. Disponível em: 
http://www.sindusnet.com.br/livre/seguranca.cfm 